\title{
Parasitoid behaviour: predicting field from laboratory
}

\author{
JEROME CASAS ${ }^{1}$, SUSAN SWARBRICK ${ }^{2}$ and WILLIAM W. MURDOCH ${ }^{2}$ \\ ${ }^{1}$ Université de Tours, Institut de Recherche en Biologie de l'Insecte, Tours, France and ${ }^{2}$ Department of Ecology, Evolution and \\ Marine Biology, University of California, Santa Barbara, U.S.A.
}

\begin{abstract}
Most of what is known about parasitoid behaviour comes from laboratory observations: field quantitative observations on searching parasitoids are extremely difficult to do and are rare. The basic components of Aphytis melinus's response to California red scale (Aonidiella aurantii) were studied in the laboratory: encounter, rejection, drumming, probing, oviposition, and hostfeeding. It was then asked whether these observations provided a reliable guide to behaviour in the field in a situation that was very different from the laboratory.

2. Field observations were carried out on bark on the trunk and interior branches of trees where live scale density is extremely high in patches, dead scale make up $90 \%$ of all scale, and could be expected to interfere with Aphytis search.

3. The laboratory observations predicted well the time taken in the field for each basic event (drumming or probing) and average times spent on a scale. Also well predicted were the distributions of times spent on drumming, probing, and total time on a scale. Rejection rates were much higher in the field. Thus, the laboratory studies predicted foraging behaviour in the field with variable success; potential explanations for observed mismatch between laboratory and field and its possible larger implications are discussed.
\end{abstract}

Key words. Aphytis, Aonidiella, biological control, field, foraging behaviour, host selection, parasitoids, predator-prey.

\section{Introduction}

Most of what is known about the behaviour and ecology of parasitoids has been discovered in the laboratory (Godfray, 1994; Quicke, 1997; Casas, 2000; Hassell, 2000; van Alphen et al., 2003; Murdoch etal., 2003). This leads to the question: are laboratory studies a good guide to field behaviour? In fact, behavioural field studies of any parasitoid species remain rare compared to the large number of laboratory studies, despite a recent surge in interest (Waage, 1983; Thompson, 1986; Casas, 1989; Janssen, 1989; Rosenheim etal., 1989; Antolin \& Strand, 1992; Driessen \& Hemerik, 1992; Connor \& Cargain, 1994; Völkl, 1994; Fauvergue etal., 1995; Heimpel et al., 1996; Casas et al., 2000; Geervliet et al., 2000; Althof \& Thompson, 2001; Bezemer \& Mills, 2003; Casas et al., 2003; Desouhant et al., 2003; Umbahhowar et al., 2003).

Correspondence: Jérôme Casas, Université de Tours, Institut de Recherche en Biologie de l'Insecte, IRBI UMR CNRS 6035, Avenue Monge, 37200 Tours, France. E-mail: casas@univ-tours.fr
Aphytis melinus DeBach (Hymenoptera: Aphelinidae) is a highly successful biological control agent of California red scale, Aonidiella aurantii (Maskell) (Homoptera: Diaspididae), a worldwide pest of citrus. Models of the interaction suggest that success may depend on how individual Aphytis respond in the field to the age-structured population of red scale (e.g. Murdoch et al., 1996, 1997). These responses have been much studied in the laboratory. It would therefore be useful to know, for this species in particular, if the laboratory is a good guide to the field.

A common approach to analysing behaviour in the laboratory is to break it down into basic components and to determine how each responds to factors that might be important in the field (Casas, 2000). Behaviour in the field is the combination of these components in many different sequences, and the combinations of environmental factors affecting such behaviour vary in time and space. Laboratory experiments do not seek to replicate these combinations, but to determine how the parasitoid responds to each factor, in the hope that behaviour can be predicted under the varying field combinations. In fact, one might expect more behavioural plasticity in the field than in the 
laboratory because field conditions are so stochastic (see Roitberg et al., 1993 for an example of behavioural changes as function of varying barometric pressure).

In this study, the key environmental factors investigated are types of scale. Scale pass through different instars, and the mixture of instars on the tree varies enormously from point to point. Furthermore, the density of scale, and especially of dead scale, varies hugely across leaves, stems, and interior bark (Murdoch et al., 1989).

The study has the following structure. Aphytis behaviour was divided into components that together comprise a sequence. In the laboratory the probability of each step in the sequence, and the duration of each type of behaviour, was estimated on different classes of scale. The behaviour of individual Aphytis was then examined in the field on bark in the tree's interior. It was asked (1) whether the durations of the basic components were similar to those estimated in the laboratory, (2) whether the way Aphytis distributes its time in the field among different individual behavioural components could be predicted, and (3) how various rates (e.g. of rejection) compared in the laboratory and field.

Laboratory studies on Aphytis typically have been done on low-density scale on fruit (lemons), with no dead scale present. Field observations on Aphytis (which is $<1 \mathrm{~mm}$ long), however, were only possible in the interior of trees, where living scale are dense and are in a virtual carpet of more abundant dead scale. These differences between laboratory and field thus expose the laboratory predictions to a severe test.

\section{Materials and methods}

\section{Behavioural observations in the laboratory}

California red scale were raised on lemons in the laboratory at $25^{\circ} \mathrm{C}, 55 \% \mathrm{RH}$ and a LD 12:12 h photoperiod. Each mixture of scale stages on a lemon was obtained by exposing lemons at appropriate intervals to crawler-producing female scale. Scale were restricted to a $24 \mathrm{~cm}^{2}$ area on the upper surface of the lemon and the remaining surface was covered with wax to prevent desiccation of the fruit. The spatial distribution of scale on a lemon was haphazard except that scale did not touch each other. Aphytis melinus were obtained from a laboratory culture established with pupae gathered at the field site in a grapefruit grove in Fillmore, California, and were maintained on red scale at $25^{\circ} \mathrm{C}$ and a LD 12:12 h photoperiod. Late-stage Aphytis pupae were removed from scale and held in $0.9-\mathrm{ml}$ vials until they emerged. Females were mated and kept in vials with a drop of honey, but without scale, until they were $48 \mathrm{~h}$ old. A female was then placed on a lemon with the same mixture of scale stages to be used in observations, and was allowed to host-feed and oviposit freely for 2 days. Thus all female Aphytis used in observations were mated, 2-4 days old, and experienced with scale.

To estimate the sequence of behavioural events and the time spent in various activities, each female Aphytis was placed on a lemon inside an arena with the appropriate mixture of scale stages. Aphytis behaviour was followed using a dissecting microscope at 6-12 power and timed with an event recorder. All scale had been mapped and numbered. Arenas were cardboard rings, $5.5 \mathrm{~cm}$ in diameter and $2 \mathrm{~cm}$ high, attached to the perimeter of the lemon with inert clay and covered with clear plastic film.

\section{Durations of events and times spent per scale}

Seven separate behavioural components were identified and timed: (1) resting, (2) searching, (3) contacting and then leaving a scale without apparent further examination, (4) drumming, (5) probing, (6) ovipositing, and (7) host-feeding on a scale. An Aphytis drums a scale by positioning herself on the scale cover and moving from the centre to the edge while tapping the cover with her antennae and sometimes her mouthparts (van Lenteren, 1994). Aphytis may further investigate the host by probing, which includes using her ovipositor to drill through the scale cover, explore the cavity between the scale body and cover, and pierce the body and explore the haemocoel. The Aphytis may leave the host at any time in this process or may go on to oviposit or consume the scale's body fluids (host-feed). Host-feeding is readily identified when, immediately after probing, the Aphytis lowers her head and positions her mouthparts over the probed area.

Only resting periods $\leq 120$ s were included in calculations of active time in the laboratory because observations of Aphytis in the field were terminated if resting was longer than $120 \mathrm{~s}$. An event was defined as a single continuous bout of drumming, probing, ovipositing, or host-feeding. If the host was rejected after drumming only, there was only one drumming event, but if probing occurred there was typically a series of alternating drumming and probing events. Oviposition was always a single event at the end of a series of drumming and probing events (i.e. the Aphytis left the scale after ovipositing), whereas host-feeding consisted of a series of alternating feeding and probing events, as the Aphytis enlarged or modified the feeding area.

In the first set of observations, each female Aphytis was given a mixture of 10 each of live first instar, female second instar, and female third-instar scale - stages Aphytis normally uses for host-feeding and/or oviposition. Density of each stage was 0.42 scale $\mathrm{cm}^{-2}$. Thirty Aphytis were used and each was observed until it had rested for at least $5 \mathrm{~min}$, but for a minimum of $1.5 \mathrm{~h}$ and a maximum of $2 \mathrm{~h}$.

In the second set of behavioural observations Aphytis were given both live and dead third-instar scale. Aphytis encounters two types of dead scale remains in the field: covers with and without bodies. Ten replicate Aphytis females were given 10 live plus 30 dead third-instar scale that had the remains of bodies under the covers, and 10 were given 10 live plus 30 dead third-instar scale covers without bodies. Thus the density of live scale was $0.42 \mathrm{~cm}^{-2}$ and the density of dead scale was $1.26 \mathrm{~cm}^{-2}$. During the observation period an individual scale could be encountered more than once, and all encounters were included in the estimates of durations of behaviours and acceptance or rejection probabilities. 
Estimation of transition probabilities and relative encounter rates

The above experiments also give the probability, for each class of scale, of the following types of behaviour: drum given an encounter, probe given drumming, oviposit (or host-feed) given probing. At each transition, failure to move to the next type of event in the sequence is the probability of rejection. The results (needed for the next section) are in Fig. 1.

The probability that an Aphytis encountered a particular scale stage, when all stages were equally abundant, was measured by placing a female Aphytis on a lemon with 10 scale of each of four stages: first instar, male second instar, female second instar, and female third instar. Seventeen female Aphytis were used, each with a new set of 40 scale. Each Aphytis was observed for $90 \mathrm{~min}$ and all encounters with scale were recorded and stage noted. During the observation period an individual scale could have been encountered more than once and each encounter was included in the tally.

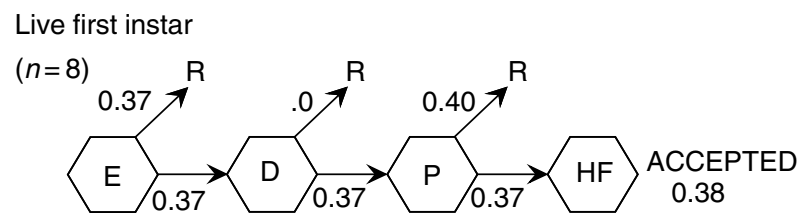

Live second instar

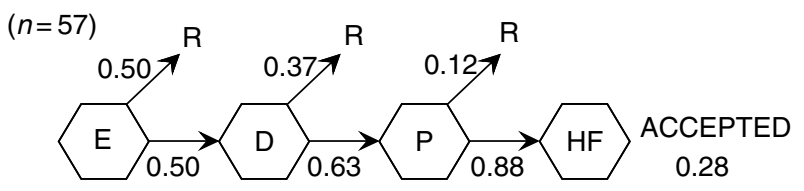

Live third instar

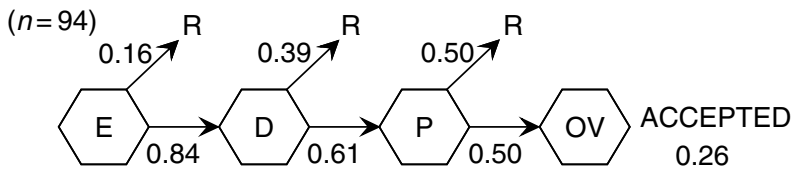

Dead third instar

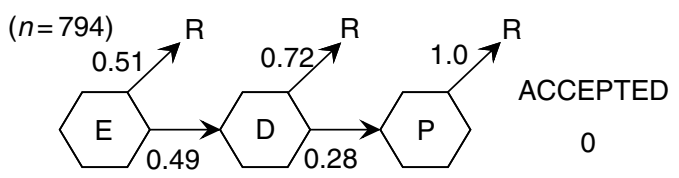

Fig. 1. Probabilities of each of a sequence of events, estimated during observations of Aphytis melinus in the presence of scale in the laboratory. In each case the probability of the event is below the appropriate arrow, and the probability the sequence was terminated at that point $(1-$ the probability of the event) is above the symbol for the event. The events are: E, examine the scale; D, drum; $\mathrm{P}$, probe; HF, host-feed; R, reject and OV, oviposit. $n$ is the number of scale (live or dead) encountered in each stage. The fraction accepted is the proportion of scale encountered that was accepted for host-feeding or oviposition. The experimental details are described in Materials and methods.
Prediction of frequency distributions of times spent in three activities in the field

In the field it could not be tested whether Aphytis dealt with each class of scale in the same way as in the laboratory, because it was not possible to determine whether each of the many hundreds of scale touched by the Aphytis was live or dead or, most of the time, what stage it was. It was therefore decided to predict the expected frequency distributions of times spent per scale in each of three activities: time spent drumming per scale, time spent probing per scale, and total time spent per scale. The duration of a single event, and the time spent on a scale doing a particular behaviour, which could consist of one or more events, are distinguished.

The calculation of predicted frequency distributions of times spent per scale on each activity in the field is explained in detail in the Appendix. It combines information on relative abundances of stages, their relative encounter rates, their sequences of transition probabilities between activities, and the time in the laboratory spent on each activity per scale in a given stage. The relative abundance of different classes of scale in the field (below) and the relative encounter rates (above) were used to calculate the distribution of expected relative encounter rates with the various types of scale.

\section{Behavioural observations in the field}

Twenty Aphytis in the interior of a tree were followed. Two modes of Aphytis behaviour were observed: a searching mode with short interspersed resting periods of 5-50 s, and a resting mode with much longer periods of inactivity ( $>2 \mathrm{~min}$ ). Timed observations were initiated as soon as a searching Aphytis was seen and terminated when the Aphytis was lost from sight or had a resting bout of $>2 \mathrm{~min}$. A total of 121 drumming and 24 probing events were observed during a total of $2 \mathrm{~h} 20 \mathrm{~min}$. Six of the 19 scale that were attacked during that period could be identified and collected. Aphytis was also observed probing eight additional scale at the study site, although not during the timed observations, and were collected and identified. Aphytis that were resting when they were first detected were not watched.

Oviposition cannot be detected accurately in the field, but in the laboratory $94 \%$ of all probing events leading to oviposition lasted $>100 \mathrm{~s}$, so events lasting $<100 \mathrm{~s}$ in the field were not classified as ovipositions.

\section{Results}

Probabilities among behavioural sequences in the laboratory

Aphytis encountered third-instar scale 3.2 times as often as first instar. Encounters with male and female secondinstar scale were equally likely; they were encountered 2.3 times as often as first instar. 
An Aphytis that encountered a scale in the laboratory did one of the following three things: (1) left it immediately without further examination, (2) examined the scale and then rejected it after drumming only or after drumming and probing, or (3) examined the scale and accepted it. Acceptance consisted of: (a) drumming, probing, and ovipositing (third instar only), or (b) drumming, probing, and host-feeding (first and second instars only). Figure 1 shows the frequency of each type of decision by Aphytis when presented with a mixture of live first-, second-, and thirdinstar scale or live and dead third-instar scale.

Since each observation on a scale is not statistically independent, hypotheses are not tested but overall patterns are commented on. Aphytis rejected roughly $70 \%$ of the live hosts encountered, and this rate did not vary much among live instars. By contrast, Aphytis rejected all dead scale Aphytis never oviposited on or tried to host-feed on a dead scale. Live first and second instar (scale stages that were ultimately host-fed) appeared to be rejected earlier in the sequence than live third instar (ultimately parasitised).

Aphytis rejected, without further examination, half of all dead third-instar scale encountered but only one-sixth of live third-instar scale. This suggests that Aphytis can sometimes distinguish live from dead scale at first contact. Probing of live scale was more frequent than dead scale: after drumming, Aphytis probed about $60 \%$ of drummed live scale but only about $27 \%$ of drummed dead scale (Fig. 1); however, some dead scale were both drummed and probed, so recognition on some occasions requires substantial investigation.

Aphytis behaviour on dead scale covers did not appear to depend on the age of the cover (1-day-old vs. 7-day-old covers). Aphytis rejected, at first contact, more covers without bodies than with bodies when both were presented in equal numbers $(62 \%$ with covers only vs. $43 \%$ with covers and bodies).

\section{Durations of events in the laboratory and field}

In the laboratory, the average probing event on live scale lasted $\approx 1.5-2 \mathrm{~min}$, and was 7-18 times longer than the average drumming event for all live stages (Table 1). In contrast, a probing event on dead third-instar scale lasted only about $13 \mathrm{~s}$ and was about three times longer than a drumming event. Both drumming and probing events were much briefer on dead third instars than on live third-instar

Table 1. Mean (+1 SE) time (s) spent by Aphytis in various activities on different scale instars that were live or dead in the laboratory and field. Average time per event is the time spent on the average single event of that kind; 24 of the probing events on live third-instar scale included oviposition, which took $9 \mathrm{~s}$ on average. Average time per examined scale is the total time spent by an Aphytis before it left the scale and may include multiple drumming, probing, and host-feeding events, but a maximum of one oviposition event. $n=$ number of events or scale observed. $\mathrm{N} / \mathrm{O}=$ not observed in the laboratory or field. One-factor ANOva was used to compare mean times among different stage/ condition (live or dead) classes for each time per event or total time category. Means with the same superscript letters were not significantly different at $P>0.05$.

\begin{tabular}{|c|c|c|c|c|c|}
\hline & Live first instar & Live second instar & Live third instar & Dead third instar & Field \\
\hline \multicolumn{6}{|l|}{ Average time per event: } \\
\hline Drumming $^{1}$ & $\begin{array}{l}4.4(1.2)^{\mathrm{a}, \mathrm{b}} \\
n=5\end{array}$ & $\begin{array}{l}9.2(0.8)^{\mathrm{a}, \mathrm{b}} \\
n=47\end{array}$ & $\begin{array}{l}14.5(3.3)^{\mathrm{b}} \\
n=262\end{array}$ & $\begin{array}{l}3.9(0.1)^{\mathrm{a}} \\
n=416\end{array}$ & $\begin{array}{l}8.4(0.7)^{\mathrm{a}, \mathrm{b}} \\
n=121\end{array}$ \\
\hline Probing $^{2}$ & $\begin{array}{l}89.6(23.0)^{\mathrm{a}, \mathrm{b}} \\
n=10\end{array}$ & $\begin{array}{l}100.1(13.0)^{\mathrm{a}} \\
n=41\end{array}$ & $\begin{array}{l}86.5(3.4)^{\mathrm{a}} \\
n=200\end{array}$ & $\begin{array}{l}13.0(0.8)^{\mathrm{c}} \\
n=131\end{array}$ & $\begin{array}{l}45.3(10.0)^{\mathrm{b}} \\
n=24\end{array}$ \\
\hline Host feeding $^{3}$ & $\begin{array}{l}95.3(28.6)^{\mathrm{a}} \\
n=7\end{array}$ & $\begin{array}{l}157.8(26.2)^{\mathrm{a}} \\
n=32\end{array}$ & $\mathrm{~N} / \mathrm{O}$ & $\mathrm{N} / \mathrm{O}$ & $\mathrm{N} / \mathrm{O}$ \\
\hline \multicolumn{6}{|l|}{$\begin{array}{l}\text { Average time per examined } \\
\text { scale when Aphytis: } \\
\text { Rejected: }\end{array}$} \\
\hline Drummed only ${ }^{4}$ & $\mathrm{~N} / \mathrm{O}$ & $\begin{array}{l}11.5(2.2)^{\mathrm{c}} \\
n=10\end{array}$ & $\begin{array}{l}13.9(2.04)^{\mathrm{c}} \\
n=31\end{array}$ & $\begin{array}{l}3.0(0.1)^{\mathrm{a}} \\
n=282\end{array}$ & $\begin{array}{l}6.8(0.8)^{\mathrm{b}} \\
n=91\end{array}$ \\
\hline Drummed + probed $^{5}$ & $\begin{array}{l}42.0(9.0)^{\mathrm{a}} \\
n=2\end{array}$ & $\begin{array}{l}57.5(23.5)^{\mathrm{a}} \\
n=2\end{array}$ & $\begin{array}{l}385.7(52.4)^{\mathrm{b}} \\
n=24\end{array}$ & $\begin{array}{l}23.2(2.2)^{\mathrm{a}} \\
n=108\end{array}$ & $\begin{array}{l}78.0(15.1)^{\mathrm{a}} \\
n=19\end{array}$ \\
\hline Accepted: & & & & & \\
\hline $\begin{array}{l}\text { Drummed, } \\
\text { Probed }+ \text { host-fed }^{6}\end{array}$ & $\begin{array}{l}500.3(76.0)^{\mathrm{a}} \\
n=3\end{array}$ & $\begin{array}{l}623.7(49.4)^{\mathrm{a}} \\
n=15\end{array}$ & $\mathrm{~N} / \mathrm{O}$ & $\mathrm{N} / \mathrm{O}$ & $\mathrm{N} / \mathrm{O}$ \\
\hline Drummed, probed + oviposited & $\mathrm{N} / \mathrm{O}$ & $\mathrm{N} / \mathrm{O}$ & $\begin{array}{l}401.3(37.5) \\
n=24\end{array}$ & $\mathrm{~N} / \mathrm{O}$ & $\mathrm{N} / \mathrm{O}$ \\
\hline
\end{tabular}

Results of one-factor ANOVA comparing event or total time among live and dead stages in the laboratory and field

1. $F_{4,846}=5.27, P=0.001, R^{2}=0.02$

2. $F_{4,401}=60.21, P<0.001, R^{2}=0.38$

3. $F_{1,37}=1.16, P=0.29, R^{2}=0.03$

4. $F_{3,410}=60.91, P<0.001, R^{2}=0.31$

5. $F_{4,150}=58.73, P<0.001, R^{2}=0.61$

6. $F_{1,16}=1.11, P=0.31, R^{2}=0.06$ 
scale. Aphytis spent only a quarter as long drumming and about one-eighth as long probing dead compared with live scale. The duration of a host-feeding event was $\approx 1.5-3 \mathrm{~min}$, and was not significantly different for first-instar and second-instar scale (Table 1).

The total time spent by Aphytis on a live scale in the laboratory varied greatly depending on whether and when the scale was rejected and, to some extent, on the stage (Table 1). Among scale that were examined by Aphytis, the parasitoid spent $<1$ min rejecting first and second instars (even if probing was involved) and also third instar provided only drumming was involved. Aphytis took as long to probe and reject as to accept and parasitise third-instar scale (about $6.5 \mathrm{~min}$, on average, $t_{46}=-0.242, P=0.81$; Table 1). First- and second-instar scale that were accepted for host-feeding were handled for about $8-10 \mathrm{~min}$ and the times for the two stages are not significantly different (Table 1). Aphytis spent longer host-feeding on a first or second instar than probing and ovipositing on a third instar (one-factor ANOvA, $F_{2,39}=6.73, P=0.003, R^{2}=0.26$; thirdinstar oviposition was significantly shorter than secondinstar host-feeding, but not significantly different from first-instar host-feeding). Very little time was spent on dead scale in the laboratory (Table 1).

During field observations it was not possible to identify the stage or condition (live or dead) of almost any scale

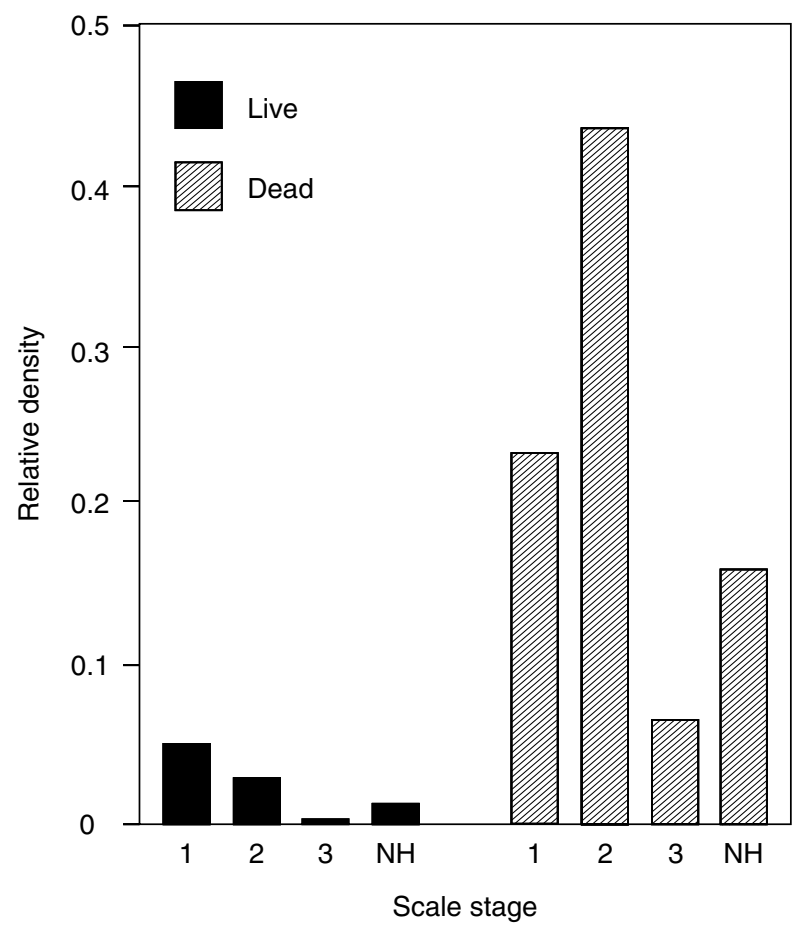

Fig. 2. Relative density of four stages of live and dead scale in samples from the bark in the interior of the observation tree. Stage 1 is first instar + moult 1 , stage 2 is male and female second instars, stage 3 is third instars, and non-hosts (NH) are moult 2 and mature plus crawler-producing scale. Density was estimated using 20 core samples as described in Murdoch et al. (1995). encountered by Aphytis. Thus the time per event and total time per scale measured in the field are averaged over an unknown mixture of live and dead scale of all stages. Nevertheless, the durations in the field, based on 110 encounters, were well within the range of those measured in the laboratory (Table 1$)$.

The mean duration of drumming events in the field was very similar to that seen in the laboratory. The duration of probing events in the field was between the values for live and dead scale measured in the laboratory, as were field measurements of the total time per scale when scale were rejected after drumming or after drumming plus probing (Table 1).

\section{Host densities in the field}

Live scale were extremely dense on bark: there were $26.5 \mathrm{~cm}^{-2}$. The density of all host stages combined was about $3 \mathrm{~cm}^{-2}$, and third instar was approximately $1 \mathrm{~cm}^{-2}$. In addition, dead scale were about nine times as abundant as live scale (Fig. 2) and $53 \%$ of the dead scale had shrivelled remains of the body under the cover.

\section{Predicted and observed behavioural frequency distributions}

The distributions of observed times spent drumming in the field are remarkably close to those predicted on the basis of laboratory observations (Fig. 3). This was confirmed by calculating the Kolmogorov-Smirnov goodness-of-fit metric, which ranges between 0 (perfect fit) and 1 (see Fig. 3). For example, it was predicted that $96 \%$ of drumming events would last 20 s or less and $89 \%$ of drumming events observed in the field were this short. No statistical tests were performed because the observations are not strictly independent.

The distributions are highly skewed because most encounters in the field were with dead scale. Dead scale in both laboratory and field were mainly drummed, and always for a short time in both situations. The good match shows that the laboratory estimates for each scale stage, of relative encounter rate and relative rate of rejection, as well as the durations of events, predict well these rates in the field. Major error in any of these would have caused a major mismatch between observed and predicted.

The fit between the observed and predicted duration of probing was not quite as good (Fig. 3) (but is based on only 19 field observations and the difference is likely not to be statistically significant). Very short $(<50 \mathrm{~s})$ probing times were somewhat less frequent than predicted in the field; $75 \%$ of events were predicted to last $50 \mathrm{~s}$ or less, and $58 \%$ of observed events were this short. Consequently, there was a slightly higher than predicted frequency of longer times (Fig. 3).

Finally, the match was again close between the observed and predicted distributions of total times (Fig. 3). For example, it was predicted that $95 \%$ of scale would be handled for a total of $50 \mathrm{~s}$ or less and $90 \%$ of those observed in the field fell within this range. The distribution was 

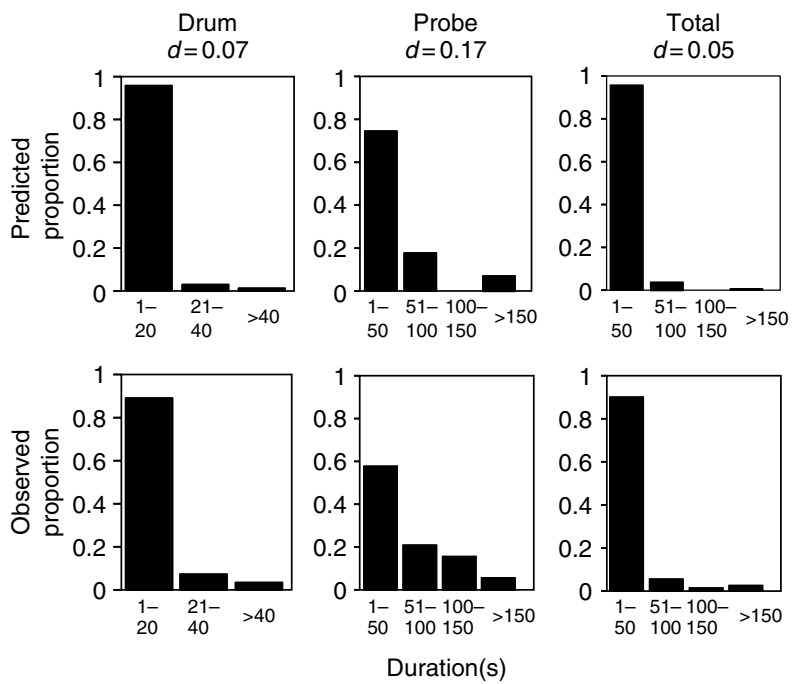

Fig. 3. A comparison of the expected and observed frequency distributions of time spent in various activities by Aphytis observed on bark in the interior of a tree. The expected distributions are based on timed behaviour in the laboratory and the relative abundance of scale stages in the field. Details are in Materials and methods. The observed distributions are from timed observations of behaviour in the field. For example, the first histogram shows the prediction that in $96 \%$ of observations in the field, Aphytis would spend $1-20 \mathrm{~s}$ drumming a scale, while $89 \%$ of the actual times spent drumming lay between 1 and $20 \mathrm{~s}$. 'Total' is the sum of the time spent on all behaviours on a scale, including drumming, probing, and oviposition or host-feeding. The $d$-values are the Kolmogorov-Smirnov statistic, which varies between 0 and 1 ( 0 being perfect agreement between observed and expected).

strongly skewed, again because of the great preponderance of dead scale in the field.

The excellent match between observed and predicted distributions of total times spent per scale is owed in part to the fact that the distribution of total time was dominated by that for drumming. But it was by no means a forgone conclusion that a good match for drumming times would lead to a good match for total times. There was also a need to predict correctly both the distribution of times spent probing and the fraction of scale that were probed.

Rates of oviposition, host-feeding, and rejection in laboratory and field

Observations of oviposition and host-feeding were relatively rare, even in the laboratory (Fig. 1), and in the field there are few observations of the former and none of the latter. Given a mixture of three stages of live hosts, Aphytis in the laboratory experiments encountered almost one scale per minute of search time, but, on average, oviposited on only 1.6 scale and host-fed on 1.2 scale per hour of active time observed. Three probing events observed in the field were longer than $100 \mathrm{~s}$, which is the laboratory-derived minimum time for a probing event that ends in oviposition. One of the scale was dissected and did not contain an egg. Since only one-third of probing events $>100 \mathrm{~s}$ in the laboratory resulted in oviposition, it may be that one, and certainly no more than two, ovipositions were observed in the field. This translates to $0.42-0.85$ ovipositions per hour in the field. A host-feeding event was not observed during the $2.3 \mathrm{~h}$ of field observations.

These observations are simply too sparse to give information about the degree of match, except that the low rates in the field are line with those observed in the laboratory. Since the average host meal probably produces more than one egg, host-feeding rates in the field are likely to be lower than oviposition rates - which is also the case in the laboratory. So it is not surprising that no host-feeding was seen.

The main mismatch between laboratory and field is in rejection rate. Aphytis had a much higher absolute rate of rejecting live scale in the field than in the laboratory. For example, in the laboratory they oviposited in $26 \%$ of the third stage encountered (Fig. 1). In the field there were on average about three live hosts per $\mathrm{cm}^{-2}$ (female and male second and third instars). Thus Aphytis in the field were literally surrounded by suitable hosts. If Aphytis had shown the same acceptance rate as in the laboratory, it would have laid its entire egg complement (up to 12 eggs) in a few minutes. In fact, Aphytis laid a maximum of only two eggs in $140 \mathrm{~min}$. These numbers suggest rejection rates of live scale might have been two or three orders of magnitude higher in the field. Dead scale, of course, were always ultimately rejected in both the laboratory and field. But half of the dead scale encountered in the laboratory were examined further, which was about the same as for live first and second instars, so Aphytis does not appear to be able to distinguish dead scale with much certainty in these laboratory conditions. Nine of the 14 scale examined in the field were dead.

In the field, Aphytis was also far less likely to spend any time examining an encountered scale. In the laboratory, only one-sixth of live hosts encountered were rejected without further examination, and fully half of encountered dead scale were examined further (Fig. 1). Scale were too dense in the tree interior to count the number of contacts, but Aphytis was clearly seen to walk over literally dozens of scale before examining one. The fraction of encounters leading to examinations in the field was certainly lower by at least an order of magnitude than in the laboratory.

\section{Time spent on dead scale in the field}

Aphytis seem to divert no more than about 20\% of potential search time to handling dead scale in the interior. Aphytis encountered dead scale approximately 10 times more frequently than live scale in field observations. In the laboratory, the mean time spent handling a live scale was $211 \mathrm{~s}$ while the time spent per dead scale was only $8.6 \mathrm{~s}$. This suggests that about $30 \%(86 \mathrm{~s} / 291.6 \mathrm{~s})$ of the time Aphytis 
was observed handling scale in the field was spent on dead scale. In the field, Aphytis spent about $33 \%$ of the total observation time handling scale, so about $10 \%$ of the total observation time was spent handling dead scale. Aphytis spent $50 \%$ of the total observation time searching (about $17 \%$ was spent in short resting bouts). Thus, if all of the time wasted on handling dead scale had been devoted instead to searching, Aphytis could have increased search time by about $20 \%$. However, this calculation overestimates the fractional time wasted on dead scale. Aphytis that were resting when first observed were not followed, nor were they observed once they had rested for $2 \mathrm{~min}$ (Materials and methods), so Aphytis were resting an unmeasured but substantial fraction of their potential search time in the field.

\section{Discussion}

It appears that observations of Aphytis behaviour in the laboratory, under intentionally artificial and simpler conditions than the field, provide reliable information on several aspects of the behaviour of Aphytis in the field. This includes the duration of the main behavioural events - drumming and probing - and the relative frequency distributions of times spent drumming and of the total time spent per scale. The frequency of short probing times per scale in the field may have been over-predicted, though this is not likely to be a statistically significant difference. If the discrepancy is real, it probably arose because Aphytis were much more likely to probe a dead scale in the laboratory (but did so only briefly) than in the field. A likely explanation for this difference is that the concentration of scale kairomone (which stimulates Aphytis to investigate scale) was higher in the confined air of the laboratory arena than in the field (Hare \& Luck, 1994; Morgan \& Hare, 1997, 1998). D. Hare (pers. comm.) has shown that free scale kairomone is stable at room temperature for months, if not years. He has also shown that Aphytis will probe filter paper disks treated with purified kairomone, and both he and this study observed Aphytis probing bark where scale had been but were no longer present (a whitish area remains).

The main difference between laboratory and field is that absolute rejection rates, including rejection of live scale, were much higher in the field. This may reflect the fact that $90 \%$ of encounters in the field were with dead scale. The instantaneous rejection rate may increase greatly when relative reward rates are low. Aphytis may also be more selective when live scale are more dense, and this may increase selectivity independent of the abundance of dead scale. Murdoch etal. (1989; Table 3), showed that in the exterior, where scale are scarce, second-instar scale were parasitised at half the rate of third instar, whereas on interior bark, where scale density is much higher, second instar were parasitised at only $10 \%$ of the rate of third instar. Since Aphytis produces only about six mature eggs per day (Casas etal., 2000), and since larger scale produce more female and larger adult Aphytis, a high rejection rate at high scale density is likely to be of selective advantage. In spite of this high rejection rate, however, most scale examined by Aphytis and brought back to the laboratory were dead. Thus Aphytis cannot infallibly and immediately distinguish dead from live scale in either the laboratory or the field, though it only takes it an average of $5 \mathrm{~s}$ to reject dead scale that it does investigate.

These results may have implications also for many other host parasitoid systems. For example, good host-size discrimination has been described in the laboratory for many parasitoids (Godfray, 1994). For Aphytis, it has been demonstrated in particular in the context of host selection, sex allocation, superparasitism, and host-feeding (Luck \& Podoler, 1985; Opp \& Luck, 1986; Yu \& Luck, 1988). But these abilities may be blunted in the field in circumstances such as those described here, where dead hosts may increase total host density to values that are so high that host examination becomes an exception (and where the substrate is less preferred). A reduction in such abilities may in turn influence population dynamics, since parasitoid behaviour and distinctions among scale stages may well be central to these dynamics (Murdoch etal., 1996, 1997, 2003). Thus, one of the larger implications of the findings is that the presence of dead hosts should not be ignored, as they may change parasitoid behaviour due either to their intrinsic qualities or because their presence changes live-host handling decisions. Dead hosts are common in several other systems. For example, Aphytis aonidiae, a parasitoid of San Jose scale on almond trees, also spent time examining dead scale in the field. About $21 \%$ of scale examined for more than $60 \mathrm{~s}$ were dead and the percentage was higher for shorter encounters (Heimpel et al., 1996; G. Heimpel, pers. comm.). A high density of unsuitable hosts was also identified as a major impediment to the success of parasitoids in two field studies of totally unrelated systems, namely leaf miners (Casas, 1989; Connor \& Cargain, 1994).

The predictions were successful for most of the behaviour, which is surprising given the huge difference between the laboratory and field conditions. It is suspected that the predictions would be on even closer match in most of the field environment - the exterior of trees - where conditions are quite similar to those in the laboratory. In particular, dead scale in the exterior of the tree are at a density of only $0.015 \mathrm{~cm}^{-2}$ and are unlikely to have much effect on behaviour, and the substrates in the laboratory and exterior of the tree are preferred by Aphytis.

Clearly more studies are needed that compare parasitoid behaviour in the laboratory and field, in particular in relationship to reproductive decisions. After a long period of purely observational studies in the field, it is encouraging to see manipulative studies being increasingly conducted (Casas et al., 2003; Desouhant et al., 2003). This study goes one step further by venturing into quantitative predictions and offers good support for the projection of laboratory studies to the field (see Geervliet et al., 2000 for qualitative predictions). Inevitably most studies will, however, continue to be done in the laboratory, and science would benefit by being more certain of their relevance. 


\section{Acknowledgements}

This study was supported by the Swiss National Science Foundation NF-823 A-037138 grant to J. Casas, and the US National Science Foundation Grants NSF DEB94-20286 and DEB00-89515 to W. W. Murdoch. We thank two anonymous referees for their comments on a previous version of the paper.

\section{References}

van Alphen, J.J.M., Bernstein, C. \& Driessen, G. (2003) Information acquisition and time allocation in insect parasitoids. Trends in Ecology and Evolution, 18, 81-87.

Althof, D.M. \& Thompson, J.N. (2001) Geographic structure in the searching behaviour of a specialist parasitoid: combining molecular and behavioural approaches. Journal of Evolutionary Biology, 14, 406-417.

Antolin, M.F. \& Strand, M.R. (1992) Mating system of Bracon hebetor (Hymenoptera, Braconidae). Ecological Entomology, 17, $1-7$.

Bezemer, T.M. \& Mills, N.J. (2003) Clutch size decisions of a gregarious parasitoid under laboratory and field conditions. Animal Behaviour, 66, 1119-1128.

Casas, J. (1989) Foraging behaviour of a leafminer parasitoid in the field. Ecological Entomology, 14, 257-265.

Casas, J. (2000) Host location and selection in the field. Parasitoid Population Biology (ed. by M. E. Hochberg and A. R. Ives), pp. 17-26. Princeton University Press, Princeton, New Jersey.

Casas, J., Driessen, G., Mandon, N., Wielaard, S., Deshouant, E., van Alphen, J.J.M. et al. (2003) Energy dynamics in a parasitoid foraging in the wild. Journal of Animal Ecology, 72, 691-697.

Casas, J., Nisbet, R.M., Swarbrick, S. \& Murdoch, W.W. (2000) Eggload dynamics and oviposition rate in a wild population of a parasitic wasp. Journal of Animal Ecology, 69, 185-193.

Connor, E.F. \& Cargain, M.J. (1994) Density-related foraging behaviour in Closterocerus tricinctus, a parasitoid of the leafmining moth, Cameria hamadryadella. Ecological Entomology, 19, 327-334.

Desouhant, E., Driessen, G., Lapchin, L., Wielaard, S. \& Bernstein, C. (2003) Dispersal between host populations in field conditions: navigation rules in the parasitoid Venturia canescens. Ecological Entomology, 28, 257-267.

Driessen, G. \& Hemerik, L. (1992) The time and egg budget of Leptopilina clavipes, a parasitoid of larval Drosophila. Ecological Entomology, 17, 17-27.

Fauvergue, X., Hopper, K.R. \& Antolin, M.F. (1995) Mate finding via a trail sex pheromone by a parasitoid wasp. Proceedings of the National Academy of Sciences of the United States of America, 92, 900-904.

Geervliet, J.B.F., Verdel, M.S.W., Snellen, H., Schaub, J., Dicke, M. \& Vet, L.E.M. (2000) Coexistence and niche segregation by field populations of the parasitoids Cotesia glomerata and C. rubecula in the Netherlands: predicting field performance from laboratory data. Oecologia, 124, 55-63.

Godfray, H.C.J. (1994) Parasitoids - Behavioural and Evolutionary Ecology. Princeton University Press, Princeton, New Jersey.

Hare, J.D. \& Luck, R.F. (1994) Environmental variation in physical and chemical cues used by the parasitic wasp, Aphytis melinus, for host recognition. Entomologia experimentalis et applicata, 72, 97-108.

Hassel, M.P. (2000) The Spatial and Temporal Dynamics of Host Parasitoid Interactions. Oxford University Press, Oxford.
Heimpel, G.E., Rosenheim, A.J. \& Mangel, M. (1996) Egg limitation, host quality, and dynamic behaviour by a parasitoid in the field. Ecology, 77, 2410-2420.

Janssen, A. (1989) Optimal host selection by Drosophila parasitoids in the field. Functional Ecology, 3, 469-479.

van Lenteren, J.C. (1994) Oviposition behaviour of Aphytis. Advances in the Study of Aphytis (ed. by D. Rosen), pp. 13-40. Intercept, Andover, U.K.

Luck, R.F. \& Podoler, H. (1985) Competitive exclusion of Aphytis lingnanensis by Aphytis melinus: potential role of host size. Ecology, 66, 904-913.

Morgan, D.J.W. \& Hare, J.D. (1997) Uncoupling physical and chemical cues: the independent roles of scale cover size and kairomone concentration on host selection by Aphytis melinus DeBach (Hymenoptera: Aphelinidae). Journal of Insect Behaviour, 10, 679-694.

Morgan, D.J.W. \& Hare, J.D. (1998) Innate and learned cues: scale cover selection by Aphytis melinus DeBach (Hymenoptera: Aphelinidae). Journal of Insect Behaviour, 11, 463-479.

Murdoch, W.W., Briggs, C.J. \& Nisbet, R.M. (1996) Competitive displacement and biological control in parasitoids: a model. American Naturalist, 148, 807-826.

Murdoch, W.W., Briggs, C.J. \& Nisbet, R.M. (1997) Dynamical effects of host size- and parasitoid state-dependent attacks by parasitoids. Journal of Animal Ecology, 66, 542-556.

Murdoch, W.W., Briggs, C.J. \& Nisbet, R.M. (2003) ConsumerResource Dynamics. Princeton University Press, Princeton, New Jersey.

Murdoch, W.W., Luck, R.F., Swarbrick, S.L., Walde, S., Yu, D.S. \& Reeve, J.D. (1995) Regulation of an insect population under biological control. Ecology, 76, 206-217.

Murdoch, W.W., Luck, R.F., Walde, S.J., Reeve, J.D. \& Yu, D.S. (1989) A refuge for red scale under control by Aphytis: structural aspects. Ecology, 70, 1707-1714.

Opp, S.B. \& Luck, R.F. (1986) Effects of host size on selected fitness components of Aphytis melinus and A. lingnanensis (Hymenoptera: Aphelindidae). Annals of the Entomological Society of America, 79, 700-704.

Quicke, D. (1997) Parasitic Wasps. Chapman \& Hall, London.

Roitberg, B., Sircom, J., Roitberg, C., van Alphen, J. \& Mangel, M. (1993) Life expectancy and reproduction. Nature, 364, 108.

Rosenheim, J.A., Meade, T., Powch, I.G. \& Schoenig, S.E. (1989) Aggregation by foraging insect parasitoids in response to local variations in host density: determining the dimensions of a host patch. Journal of Animal Ecology, 58, 101-117.

Thompson, J.N. (1986) Oviposition behaviour and searching efficiency in a natural population of a braconid parasitoid. Journal of Animal Ecology, 55, 351-360.

Umbahhowar, J., Maron, J. \& Harrison, S. (2003) Densitydependent foraging behaviours in a parasitoid lead to density-dependent parasitism of its host. Oecologia, 137, 123-130.

Völkl, W. (1994) Searching at different spatial scales: the foraging behaviour of the aphid parasitoid Aphidius rosae in rose bushes. Oecologia, 100, 177-183.

Waage, J. (1983) Aggregation in field parasitoid populations: foraging time allocation by a population of Diadegma (Hymenoptera, Ichneumonidae). Ecological Entomology, 8, 447-453.

Yu, D.S. \& Luck, R.F. (1988) Temperature dependent size and development of California red scale (Homoptera: Diaspididae) and its effect on host availability for the ectoparasitoid Aphytis melinus. Environmental Entomology, 17, 154-161.

Accepted 9 March 2004 


\section{Appendix: calculation of predicted frequency distributions in the field}

Here the derivation of predicted frequency distributions of times spent by Aphytis in three activities in the field is explained. The first three steps calculate the predicted probability that a scale that is examined (i.e. at least drummed) in the field is of stage $i$, using the observed relative abundances of scale stages in the field, and encounter and immediate rejection probabilities from the laboratory. Step 4 uses observed probabilities of probing, given drumming, to compute the probability a scale will be probed. Steps 5 and 6 combine the predicted probabilities of drumming and probing with laboratory data to calculate the distributions of times spent by Aphytis in each activity on each scale stage.

1 Predicted frequency of encountering a scale of stage i. Fig. 2 shows the estimated relative abundance of each scale stage in the field, $N_{i}$. However, a large scale is more likely to be encountered than a small scale, so the predicted relative frequency of encountering each stage, $N_{i} e_{i}$, is its relative abundance weighted by its laboratory-derived relative encounter rate, $e_{i}$. The value of $e_{i}$ obtained for third instars was applied to mature and crawler producing females, and dead scale were given the same value of $e_{i}$ as live scale.

2 Predicted relative frequency of drumming a scale of stage $\mathrm{i}$. The first transition rate $(\mathrm{E} \rightarrow \mathrm{D})$ in Fig. 1 shows the estimated rate of at least initial acceptance, $a_{i}$, for each of four scale stages. That is, all scale that were not rejected immediately on encounter were at least drummed. The relative frequency of drumming a scale of stage $i$ is thus $N_{i} e_{i} a_{i}$. The value of $a_{i}$ obtained for third instars was applied to mature and crawler producing females, and all dead instars had the value of $a_{i}$ obtained for dead third instar.
3 Predicted probability distribution that a drummed scale is of stage i. This step simply transforms the previous relative frequencies into a probability distribution. That is, $D_{i}=N_{i} e_{i} a_{i} / \Sigma N_{i} e_{i} a_{i}$ is the probability that, in the field, a drummed stage is in stage $i$.

4 Predicted probability distribution that a probed scale is of stage $i$. The second transition $(\mathrm{D} \rightarrow \mathrm{P})$ in Fig. 1 shows the fraction of scale of stage $i$ that were probed, given that they were drummed. Multiplying this by the fraction drummed gives the fraction of those encountered that were probed, $p_{i}$. As in step 3 , the predicted probability that a probed scale in the field is in stage $i$ is then $P_{i}=N_{i} e_{i} p_{i} / \Sigma N_{i} e_{i} p_{i}$

5 Laboratory-observed frequency distribution, $\mathrm{F}_{\mathrm{i}}(\mathrm{j})$, of times spent on activity $\mathrm{j}$ on scale of stage $\mathrm{i}$. The different activities are now introduced: drumming times spent per scale, probing times spent per scale, and total times spent per scale. The laboratory experiments give, for a given activity, $j$, being carried out on stage $i$, the distribution of times spent on the activity.

6 Predicted relative frequency distribution, $F_{i}(j) P_{i}$, of time spent on activity $\mathrm{j}$ on scale of stage $\mathrm{i}$. This step simply weights $F_{i}(j)$ with $D_{i}$ and $P_{i}$, the predicted probabilities respectively, that drummed only, or probed, scale is of stage $i$. The frequency distribution of total times on scale is multiplied by $D_{i}$ since this is the probability the scale is examined at all.

7 Predicted relative frequency distribution of time spent on activity j. Finally, the distributions of times that all Aphytis encountering scale at random in the field should exhibit are predicted, summing across scale stages for each of the activities, to give $\Sigma F_{i}(j) P_{i}$. The various distributions have been combined so that this final sum is a probability distribution, i.e. $\Sigma F_{i}(j) P_{i}=1$. 